\title{
A Review on Design, Simulation and Implementation of Single Phase Hybrid Active Power Filter
}

\author{
Chetana Praful Sangani ${ }^{1}$, Yatin N Mistry ${ }^{2}$, Mayur M Bhesaniya ${ }^{3}$, Sharavan B Gaund ${ }^{4}$, Utsav V Patel ${ }^{5}$ \\ Department of Electrical Engineering, Valia Institute of Technology, Bharuch, Gujarat, India
}

\begin{abstract}
This paper represent the problem of quality electrical energy provided to the users has arisen. This is due to the increasing presence in network of nonlinear loads. They constitute a harmonic pollution source of the network, which generate many disturbances, and disturb the optimal operation of electrical equipments. This work, proposed a solution to eliminate the harmonics introduced by the nonlinear loads. It presents the analysis and simulation using Matlab Simulink of a hybrid active power filter (hapf) compensating the harmonics and reactive power created by nonlinear loads in steady and in transients. The usefulness of the simulation approach to hapf is demonstrated, have a better power quality insight using Matlab Simulink.
\end{abstract}

Keyword: Matlab simulation, active filter, passive filter,

\section{Introduction}

A harmonic is a signal or wave whose frequency is an integral (whole-number) multiple of the frequency of some reference signal or wave. The term can also refer to the ratio of the frequency of such a signal or wave to the frequency of the reference signal or wave.

Harmonics are the mathematical way of describing distortion to a voltage or current waveform. The term harmonic referred to a component to a waveform that occurs at integer multiple of the fundamental frequency. Fourier theory tell us that any repetitive waveform in define in term of summing sinusoidal waveform which are integer multiple of the fundamental frequency. For the purpose of the steady state waveform with equal positive and negative half cycle.

For example, if the fundamental power frequency is $50 \mathrm{~Hz}$, then the $2^{\text {nd }}$ harmonic is $100 \mathrm{~Hz}$, the $3^{\text {rd }}$ is $150 \mathrm{~Hz}$, etc. In modern test equipment today harmonics can be measured up to the $63^{\text {rd }}$ harmonic. When harmonic frequencies are prevalent, electrical power panels and transformers become mechanically resonant to the magnetic fields generated by higher frequency harmonics. When this happens, the power panel or transformer vibrates and emits a buzzing sound for the different harmonic frequencies. Harmonic frequencies from the $3^{\text {rd }}$ to the $25^{\text {th }}$ are the most common range of frequencies measured in electrical distribution or in power electronics systems.

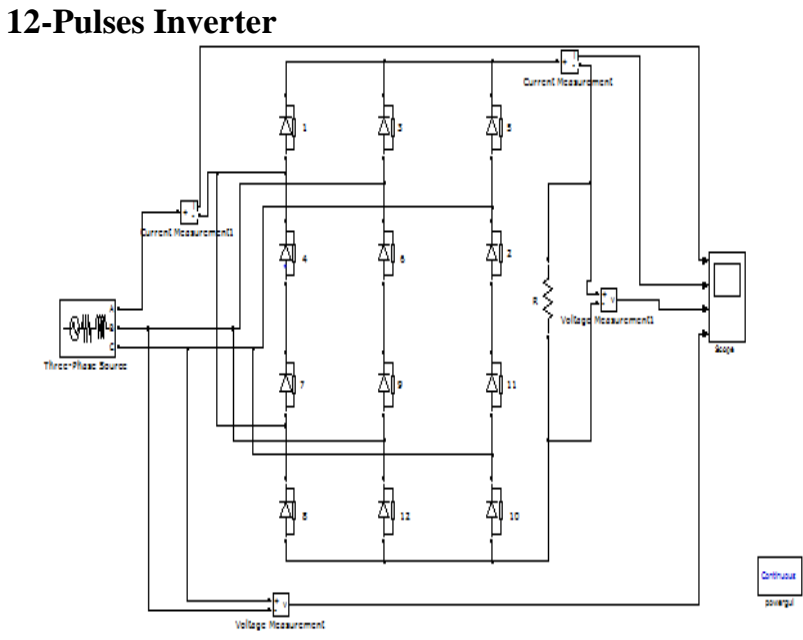

[12-PULSE MULTILEVEL INVERTER]

Here the simulation of the 12 pulse inverter is shown. There total 12 diode are used. This is connected to the 1-phase supply. By the switching operation we get the waveform which is shown in the below.

Where the first waveform is the IL1 is line current and we get the sine wave in the output. Now in the IL2 is the current is passed through the diode. as shown in the waveform first the diode is in the transient because first the diode worked as forward bias and that time the capacitor is initially charged so we get the transient waveform and then the capacitor is fully charged and release the energy so we get the near to steady state waveform. Here the point 0.01 the transient occur then to the point 0.06 and 0.07 we get the stable form. 
International Journal of Science and Research (IJSR)

ISSN (Online): 2319-7064

Index Copernicus Value (2013): 6.14 | Impact Factor (2015): 6.391
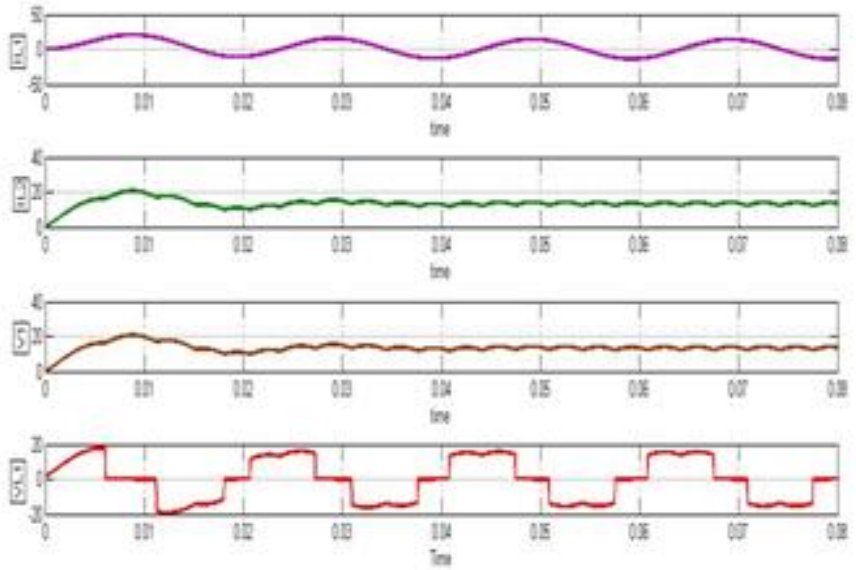

[Waveform of 12 pulse inverter]

\section{Block diagram of the HAPF}

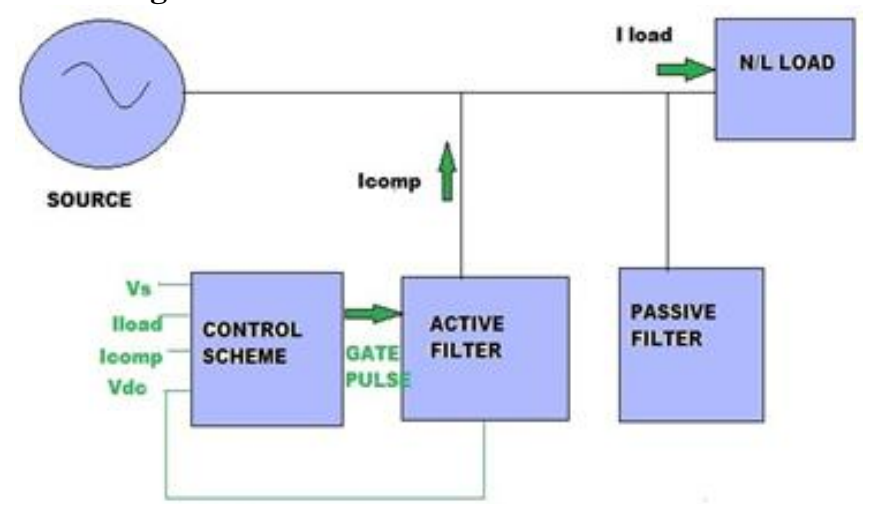

[Block diagram of HAPF]

\section{Simulation of Hybrid Active Power Filter}

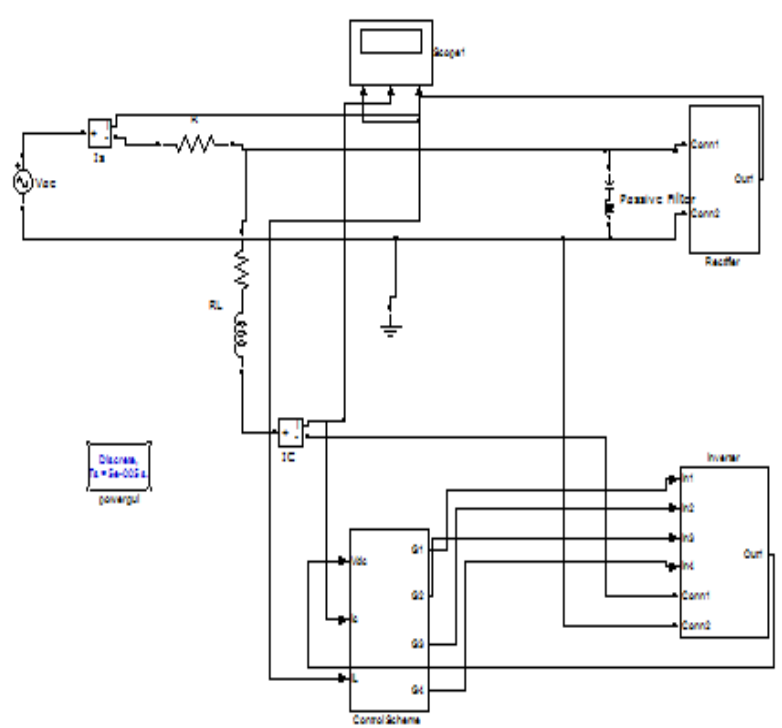

[Simulation of HAPF]

Here, the simulation of single phase hybrid active power filter is shown. Between source and rectifier in shunt active and passive filter are connected. In control scheme we use hysteresis current control scheme. Here we use rectifier as a non- near load.
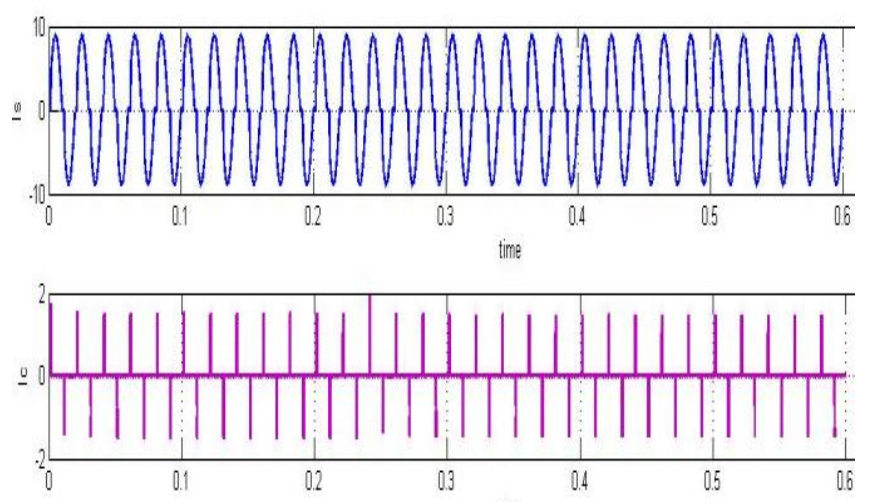

time

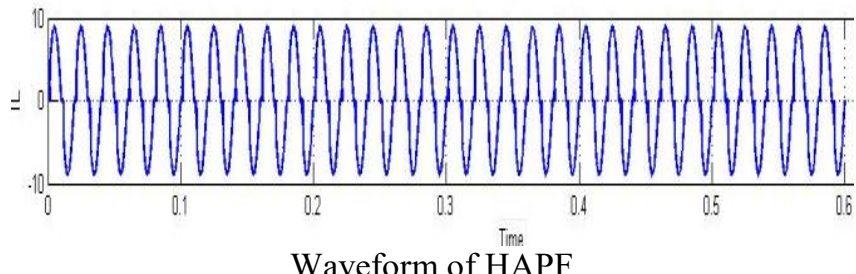

Waveform of HAPF

12-Pulse Converter with Filter

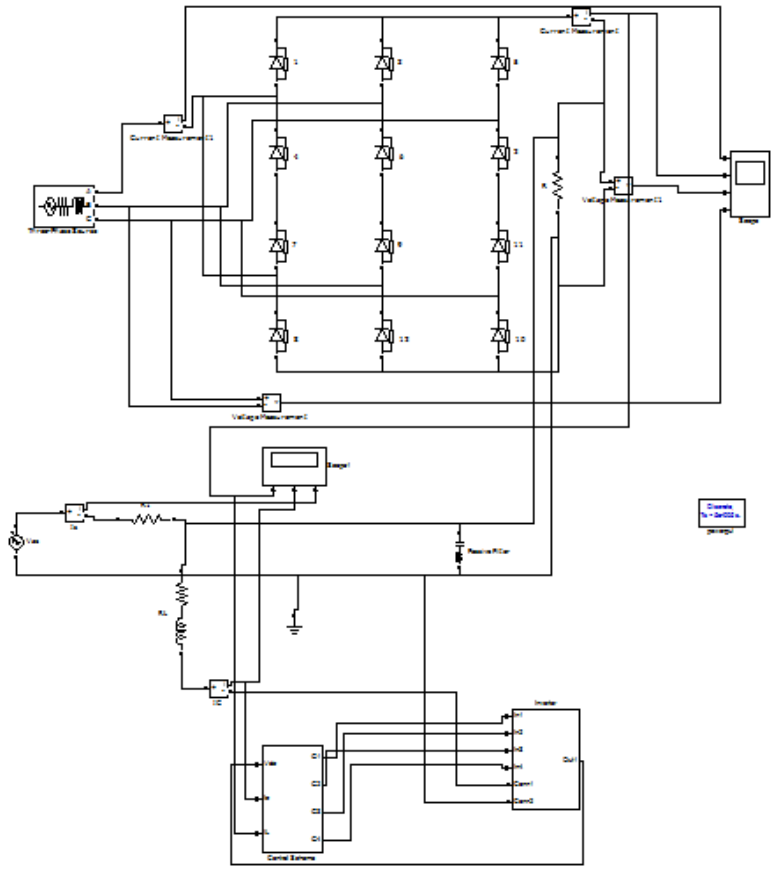

[12 pulse converter with filter]

Here, 12-pulse converter with $30^{\circ}$ and $60^{\circ}$ is with hybrid active power filter is shown. The waveform of the 12 pulse converter with filter and without filter is shown at different angels 


\section{International Journal of Science and Research (IJSR) \\ ISSN (Online): 2319-7064}

Index Copernicus Value (2013): 6.14 | Impact Factor (2015): 6.391

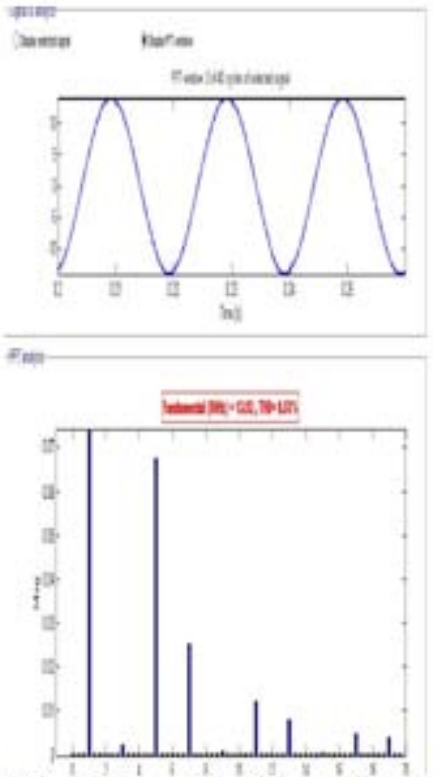

[Fig 5.1.2 a=30 without filter]
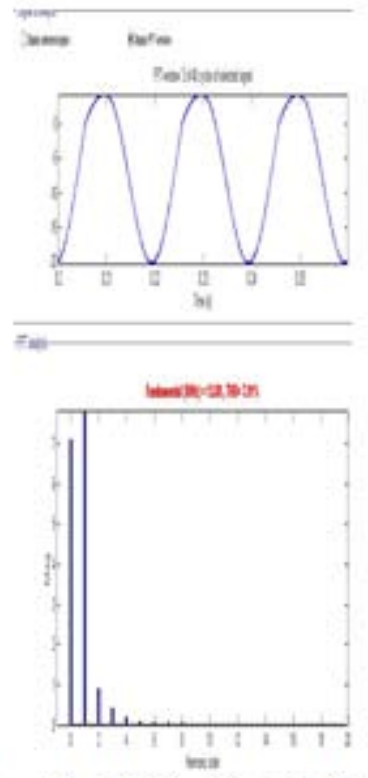

[fig $5.1 .3 \mathrm{a}=30$ with filter]

At $a=30$ without filter there were a $5^{\text {th }}$ harmonics $7^{\text {th }}$ harmonics etc. and it can be reduced by using the filter we reduced the $3^{\text {rd }}, 5^{\text {th }}, 7^{\text {th }}$ harmonics which is shown in the waveform.

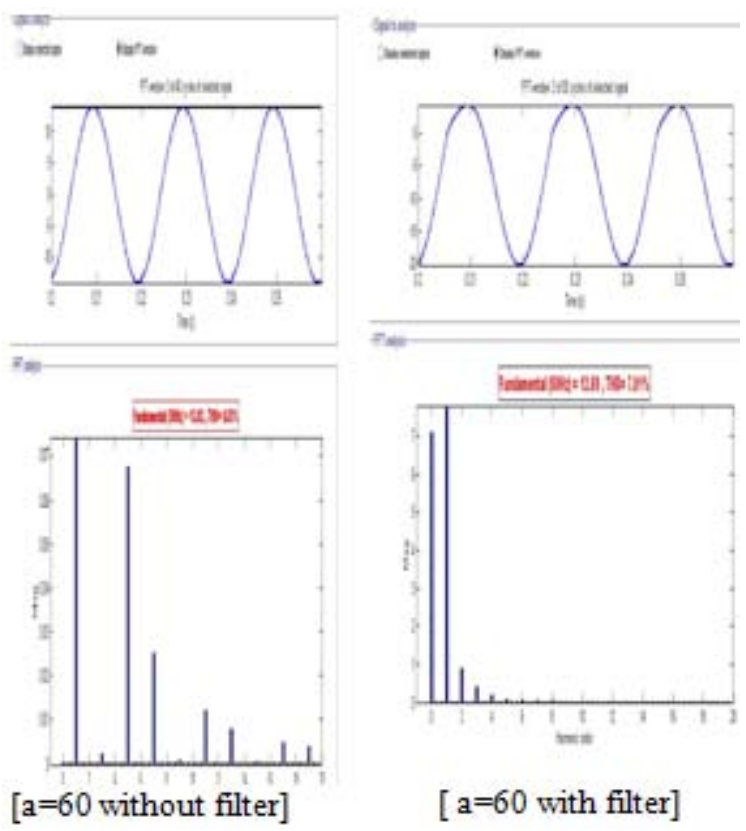

Here, $\mathrm{a}=603^{\text {rd }}, 5^{\text {th }}$ and $7^{\text {th }}$ in short all odd harmonics are reduced. Without filter THD is $8.52 \%$ and after connecting the filter THD is $7.91 \%$.

\section{Advantages}

1) The noise and the vibration of the appliance will be reduces of same amount.

2) The waveform distortion will be reduce.

3) Safety for non linear load.

4) Increase efficiency.

5) Can produce the high gains.

\section{Disadvantages}

1) Can require many components.

2) Cost is high

3) Complicated circuit

\section{Application}

- Industrial Application like motor drives for pumping the Water, chemicals, steam etc.

- For domestic purpose like lightening load, fans, TV, refrigerator etc.

\section{References}

[1] Akagi.H, 1996. "New Trends in Active Filters for Power Conditioning", IEEE Transaction on Industrial Applications, vol. 32, No 6, Dec., pp 1312-1322.

[2] Akagi.H, 2006. "Modern active filter and traditional passive filters", Bulletin of the polish academy of sciences technical sciences vol.54.No

[3] F. Z. Peng and D. J. Adams, "Harmonics sources and filtering approaches," in Proc. Industry Applications Conf., Oct. 1999, vol. 1, pp. 448-455.

[4] H. Akagi, "Active harmonic filters," Proc. IEEE, vol. 93, no. 12, pp. 2128-2141, Dec. 2005.

[5] M. Aredes, E. H. Watanabe, New Control Algorithms for Series and Shunt Three-Phase Four-Wire Active Power Filters, IEEE Trans. Power ${ }^{\wedge} \mathrm{H}$. Akagi, Y. Kanazawa, A. Nabae, Generalized Theory of the Instantaneous Reactive Power in Three-PhaseCircuits, IPEC'83 - Int. Power Electronics Conf., Tokyo, Japan, 1983, pp. 1375-1386.

[6] N. S. Choi, J. G. Cho, and G. H. Cho, "A general circuit topology of multilevel inverter," in Proc. IEEE PESC'91, 1991, pp. 96-103

[7] J. Rodriguez, J.-S. Lai, and F. Z. Peng, "Multilevel inverters: a survey of topologies, controls, and applications," IEEE Trans. Ind. Electron., vol. 49, pp. 724-738, 2002.

[8] M. Rastogi, N. Mohan, and A. A. Edris, -Hybridactive filtering of harmonic currents in power systems, IEEE Trans. Power Del., vol. 10, no.4, pp. 1994-2000, 1995.

[9] Z. Wang, Q. Wang, W. Yao, and J. Liu, -A series active power filter adopting hybrid control approach,\| IEEE Trans. Power Electron., vol. 16, no. 3, pp. 301310,200 